\title{
DIALOGULE Shaping GSA's Financial Future
}

Tony Naldrett, President, and Jack Hess, Executive Director

In a 1998 Environmental Scan, the American Society of Association Executives reported on 14 trends affecting associations, all of which presently impact GSA. This month, we highlight one of those trends- "Revenue Sources: The need for new revenue will drive associations to become more innovative in seeking out new partners and nontraditional sources of income" - and share with you how GSA is responding.

In February's "Dialogue" you read about GSA's finances and how the Society must reduce the size of its operating budget. We're now on a diet, so to speak, and you may have already noticed some changes at headquarters. While lowering expenditures is an important first step toward improving our financial health, there is more to be done. We must also increase revenue.

\section{The Current Picture}

At present, publications produce approximately one-third of GSA's total revenue. Meetings and member dues account for another third. Investment income provides about one-fifth of the total, and the GSA Foundation, grants, and other miscellaneous sources make up the balance.

If we are to maintain GSA's profile as a major earth science society beyond the next decade, we must be prepared for changes in these revenue streams.

Consider publications, for example. GSA's journals are among the most highly cited in the geosciences; they are vibrant and doing well. At the same time, we know that the structure of the publications business is changing. GSA plans to change with it by participating in an aggregate of online society journals that offers increased convenience and research horsepower. (See "Dialogue," March 2002, for details on the aggregate.)

While we are confident moving ahead, we don't know how this change in the structure of our publications business will alter the revenue stream. We do know that we cannot assume the picture will remain the same. This can be said for all of GSA's major sources of revenue, as well as for their proportional relationships to one another.

On the plus side, GSA is one of only a few scientific societies presently growing in membership. In a recent address to the Council of Scientific Society Presidents, Sharon Mosher analyzed reasons for this; she concluded that a decline that was also affecting GSA ended in 1995-1996 as a result of planned changes to address the problem. These changes involved: revamping the approach to annual meetings (which had become stuffy and regionally focused) to address significant disciplinary, interdisciplinary, and global problems (Pardee and Topical sessions); making a special effort to encourage students to join and then stay as GSA members; and bringing a more global perspective to the Society when it comes to addressing key scientific issues (e.g., the recent GSA-GSL 2001 joint meeting on earth science systems).

The open-minded, innovative approach that has been applied to meetings must be taken to the Society as a whole: As our environment changes, we must be prepared to change with it on any and all fronts.

\section{A New Entrepreneurial Spirit}

It is our view that a new entrepreneurial spirit is required within GSA. We need to look ahead, think outside the box, and plan for the future.

Recognizing this, we have formed an ad hoc Long-Range Planning Committee to investigate ways of changing GSA and adding new revenue streams from a variety of sources to meet future needs. Possible new revenue streams include a much higher income from grants; marketing and selling services to industry, the community, and government that are based on the skill set of our headquarters staff; new classes of membership; and better utilization of our building.

We have asked this committee's members to prepare an interim report by this October and a final report by May 2003. We know that they would welcome all suggestions from you, our members. Please submit your thoughts to Ann Cairns, acairns@geosociety.org, at GSA headquarters. Thank you. 